\title{
Decadal variability of northern Asian winter monsoon shaped by the 11-year solar cycle
}

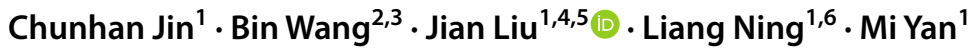

Received: 30 March 2019 / Accepted: 20 August 2019 / Published online: 3 September 2019

(c) The Author(s) 2019

\begin{abstract}
Climate signals associated with 11-year sunspot cycle have been extensively studied in various regions of the northern hemisphere, but the precise mechanisms remain elusive. Asian winter monsoon (AWM) is the most powerful circulation system on the Earth, yet its relationship with the 11-year solar cycle has not been explored. Here the response of AWM to the 11-year solar forcing is explored by analysis of numerical experiment results obtained from the Community Earth System Model-Last Millennium Ensemble (CESM-LME) modeling project. We show that a strong 11-year solar cycle can excite a resonant response of the intrinsic leading mode of the AWM variability, resulting in a significant signal of decadal variation. The leading mode, characterized by a warm Arctic and cold Siberia, responds to the maximum solar irradiance with a peculiar 3 to 4-year delay. We propose a new mechanism to explain this delayed response, in which the 11-year solar cycle affects the AWM via modulating Arctic sea ice variation during the preceding summer. At the peak of the accumulative solar irradiance (i.e., 4 years after the maximum solar irradiance), the Arctic sea ice concentration reaches a minimum over the Barents-Kara Sea region accompanied by an Arctic sea surface warming, which then persists into the following winter, causing Arctic high-pressure extend to the Ural mountain region, which enhances Siberian High and causes a bitter winter over the northern Asia.
\end{abstract}

Keywords 11-year solar cycle $\cdot$ Asian winter monsoon $\cdot$ Decadal variation $\cdot$ Arctic sea ice $\cdot$ Arctic warming

Jian Liu

jliu@njnu.edu.cn

1 Key Laboratory for Virtual Geographic Environment of Ministry of Education/State Key Laboratory of Geographical Evolution of Jiangsu Provincial Cultivation Base/Jiangsu Center for Collaborative Innovation in Geographical Information Resource Development and Application, School of Geography Science, Nanjing Normal University, Nanjing 210023, China

2 Department of Atmospheric Sciences, University of Hawaii at Manoa, Honolulu, HI 96825, USA

3 Earth System Modeling Center, Nanjing University of Information Science and Technology, Nanjing 210044, China

4 Jiangsu Provincial Key Laboratory for Numerical Simulation of Large Scale Complex Systems, School of Mathematical Science, Nanjing Normal University, Nanjing 210023, China

5 Open Studio for the Simulation of Ocean-Climate-Isotope, Qingdao National Laboratory for Marine Science and Technology, Qingdao 266237, China

6 State Key Laboratory of Loess and Quaternary Geology, Institute of Earth Environment, CAS, Xian, China

\section{Introduction}

The relationship between solar activity and Earth's weather and climate has attracted enormous attention in climate research community over the past century (Siscoe 1978). Numerous model studies have suggested that the spectrum solar irradiance interacting with ozone can strongly affect stratospheric temperature and circulation, which then propagate downward to alter tropospheric general circulation (Haigh 1996; Matthes et al. 2006). Statistical correlations between the 11-year solar activity and the decadal climate variability have been found in the observations (Currie 1993; Soon 2005; Van Loon and Meehl 2012). At the peak years of the 11-year solar cycle, the climatological precipitation maxima in the tropical Pacific were found to be strengthened, further modulating the Pacific climate system, i.e., Pacific Decadal Oscillation (PDO) and El Niño-Southern Oscillation (ENSO) (Van Loon et al. 2007; Meehl et al. 2008, 2009). While for the Northern Hemisphere (NH) winter, links between the solar 11-year variability and the North Atlantic Oscillation (NAO) have been extensively 
investigated, which result in diverse views (Ineson et al. 2011; Scaife et al. 2014; Thiéblemont et al. 2015; Gray et al. 2016; Chiodo et al. 2019).

Understanding the physical processes involved in solarclimate connections is crucial to interpretation of the observed climate variability and predictability and to the projection of future climate change. A major process of solar influence that has been identified is via a 'top-down' mechanism. The ultraviolet radiation variability on heating rates in the tropical upper stratosphere may affect the meridional temperature gradients and the zonal mean wind anomalies, which then migrate poleward and downward through wave-mean flow interaction (Haigh 1996; Andrews et al. 2015). Another mechanism is the 'bottom-up' coupled airsea mechanism. Increased total solar irradiance (TSI) over cloud-free regions of the subtropics translates into greater evaporation, and the resulting moisture is carried to the convergence zones by the trade winds, thereby strengthening the intertropical convergence zone (ITCZ), affecting the Pacific climate system (Meehl et al. 2008, 2009).

Asian winter monsoon (AWM) is the most powerful circulation system in the NH winter. Comparing with the complex structure of the Asian summer monsoon (Wang et al. 2001; Zhou et al. 2009), the surface circulation of the AWM is simply dominated by the gigantic Siberian-Mongolian High (Chang et al. 1983). Jin et al. (2019) had demonstrated that the decadal variation of the East Asian summer monsoon is possibly affected by the 11-year solar cycle through changing North Pacific decadal oscillation. It is expected that the 11-year solar cycle might also have a footprint in AWM variability. So far, the relationship between AWM and the 11-year solar cycle has not been explored. Therefore, we are curious about to what extent the 11-year solar cycle may affect AWM. In particular, what are the characteristics of AWM that are modulated by the 11-year solar cycle? If there is a linkage between them, how can an enhanced solar irradiance affect $\mathrm{NH}$ winter climate when the spot of direct sunlight moves toward the Tropic of Capricorn of the southern Hemisphere? The present work aims at addressing these questions.

It is of great difficulty to distinguish the 11-year solar cycle signal from the short-term observations of the AWM, because the amplitude of 11-year cycle is relatively small (Haigh 1996) whereas the AWM variability is affected by a variety of factors, including natural internal variability (e.g., ENSO, NAO) and other external (e.g., volcanic, anthropogenic) influences (Frame and Gray 2010; Gray et al. 2013). To isolate the impacts of the 11-year solar cycle, we analyze numerical simulation results derived from four solar-only forcing experiments and one control experiment (CTRL), which were conducted by the Community Earth System Model-Last Millennium Ensemble (CESM-LME) modeling project (Otto-Bliesner et al. 2016).
In this paper, we first explore the spatiotemporal variability of the AWM by using the monthly surface temperature data derived from the 20th Century Reanalysis V2 data provided by the NOAA/OAR/ESRL PSD (Compo et al. 2011), and then validate the model performance of the CESM in reproducing the AWM variability in Sect. 3. In Sect. 4, we explore the variation of the AWM modulated by the solar activity on decadal time scale, and examine the linkage between the decadal variation of AMW and the 11-year solar cycle. Then, the possible processes by which the 11-year solar cycle impacts the northern Asian winter are discussed in Sect. 5. In Sect. 6, we elaborate a new mechanism by which the 11-year solar cycle could affect Eurasian winter temperature by modulating the preceding summer and autumn Arctic sea ice variation. The last section presents major conclusions and discusses remaining issues.

\section{Numerical experiments and observational data}

The CESM-LME simulation data provided by NCAR's Climate Change Research Section is an ensemble of fullyforced, and single-forced simulations. In the CTRL experiment, with the fixed external forcings at AD 850, climate variations are solely arising from the coupled dynamics internal to the Earth's climate system. In the four solar-only forcing experiments, the varying solar forcing was applied but all other external forcings were fixed at the condition of AD 850. Changes in the total solar irradiance (TSI) were prescribed by the reconstructed solar forcing (Vieira et al. 2011). The four-member ensemble average derived from the solar-forcing experiments can largely reduce the noises of the internal variability, so that the impacts of solar forcing on AWM variations can be better identified by comparison with the CTRL experiment. Due to the low-top atmospheric model with no prognostic ozone chemistry in these numerical experiments, there is no response of the stratospheric ozone change to the solar intensity variation, the response to solar forcing shown here is coming from the "bottom-up" mechanism.

Figure 1 shows the wavelet analysis of the time-frequency distribution of the solar forcing used in the varying spectral solar irradiance experiments. The imposed solar forcing exhibits a significant peak on the 8 to 16 -year band, and their intensity varies with time. In order to compare the impacts of the decadal solar activity, we selected the AD 1100-1235 as an epoch with significant 8 to 15 -year solar cycles (Strong Epoch hereafter) and the period of AD $1400-1535$ as an epoch without significant 8 to 15 -year solar cycles (Weak Epoch hereafter).

In addition to the simulation results, we have used the surface air temperature derived from the 20th Century 


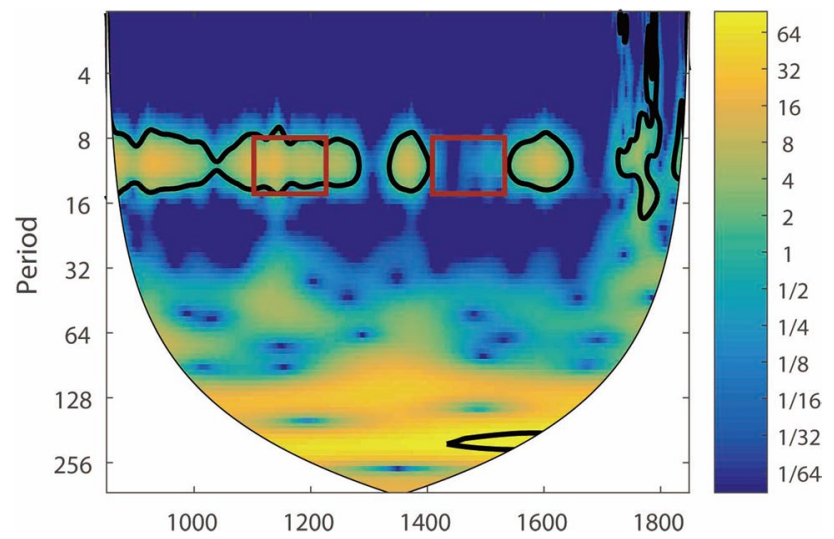

Fig. 1 Wavelet analysis of the external forcing used in the solar-only forcing experiments. The red boxes outline the two epochs selected in our comparison study

Reanalysis Project version 2 dataset during 1871-2000 to explore the characteristics of the Asian Winter Monsoon and verify the simulation results of the CESM_LME.

\section{Characteristics of the AWM in the observation and control experiment}

Previous research has shown that the interannual-to-decadal variability of the East Asian winter surface air temperature (SAT) is dominated by two distinct empirical orthogonal function (EOF) modes, the northern mode and the southern mode (Chen et al. 2014); and the two modes, although derived from the East Asian domain, also capture the winter SAT variability over the entire Asia (Wang et al. 2010). Figure $2 \mathrm{a}$ and $\mathrm{b}$ are the first two leading modes of AWM variability in December to February (DJF) mean SAT during $\mathrm{AD} 1871-2000$ over the entire Asia $\left(0-70^{\circ} \mathrm{N}, 60-140^{\circ} \mathrm{E}\right)$ derived from the 20th Century Reanalysis. The first EOF mode (EOF1) of the AWM features a uniform cold pattern between $40^{\circ} \mathrm{N}$ and $70^{\circ} \mathrm{N}$ with the largest negative anomaly around $60^{\circ} \mathrm{N}$. The second EOF mode (EOF2) displays a dipolar zonal structure over the entire Asia with the maximum cooling being located at the Kazakh Uplands and extended to East China. The EOF modes are similar to those shown in the Wang et al. (2010). Therefore, in this paper, the EOF1 is referred to as the northern mode of the AWM variability, and the EOF2 is the southern mode of the AWM variability. Since the northern mode explains about $50 \%$ of the total variance, which is about four times larger than that of the southern mode, we will focus analysis of the temporal variation of the leading (northern) mode in this study. From the power spectrum of the corresponding Principal Components (PC), the first PC (PC1) is dominated by an interannual ( 2-year) signal with a minor insignificant decadal peak (Fig. 3a).

To validate the model's capacity in reproducing AWM variability and make a fair comparison, we randomly selected a 130-year sample from the CTRL experiment. The spatial patterns of the EOFs in the control run are consistent with the corresponding observed EOF modes (Fig. 2c, d), while there exist large differences in the periodicity of the PC1 (Fig. 3). In the CTRL (Fig. 3b), the interannual energy peaks are evidently stronger than those in the observed data, and the decadal variation has a significant quasi-15-year peak. The leading mode in the CTRL represents an intrinsic internal climate variability in the model without any external forcing, which is different from the observation. Since the various forcing factors are in action in the observed record, the temporal behaviors of the leading modes in the CTRL and observation are not directly comparable. However, the model from the CESM-LME simulates realistic spatial structure of the leading modes of the AWM, suggesting that the most frequently observed spatial pattern of the SAT in the model is realistic.

\section{Evidence of 11-year solar cycle influence on decadal variation of the AWM}

To investigate how the solar activity possibly affects the AWM, a natural starting point is to see how solar forcing variation links to the variations of the two leading modes (Fig. 4). During the Strong Epoch, the first two leading modes are significantly distinguished from other modes by statistical significance test (North et al. 1982), and explain $44.1 \%$ and $14.3 \%$ of the total variance, respectively (Figs. $4 a$, b). It is of interest to note, the two EOF modes of the AWM over Asia resemble the EOF modes in the CTRL experiments and 20th Century Reanalysis. The simulated and observed EOF1modes have a comparable magnitude although the simulated magnitude is smaller than the observed one. In addition, the EOF modes during the Strong Epoch and Weak Epoch have obviously similar spatial patterns and fractional variances (Fig. 4), suggesting that the two leading modes are essentially the internal modes of variability, and their existences do not depend on external forcing. Thus, the solar forcing does not appreciably change the structures of the intrinsic modes. Then, the question is: what roles does the 11 -year solar cycle play in the AWM variation?

We then examined the power spectrum of the PC1. Figure 5 compares the spectra of the $\mathrm{PC} 1 \mathrm{~s}$ obtained from the strong and weak 11-year solar cycle epochs of the solar forcing experiment. Notably, a significant decadal signal with a peak at 12 years becomes a dominant periodicity in the PC1 during the Strong Epoch, meanwhile the 

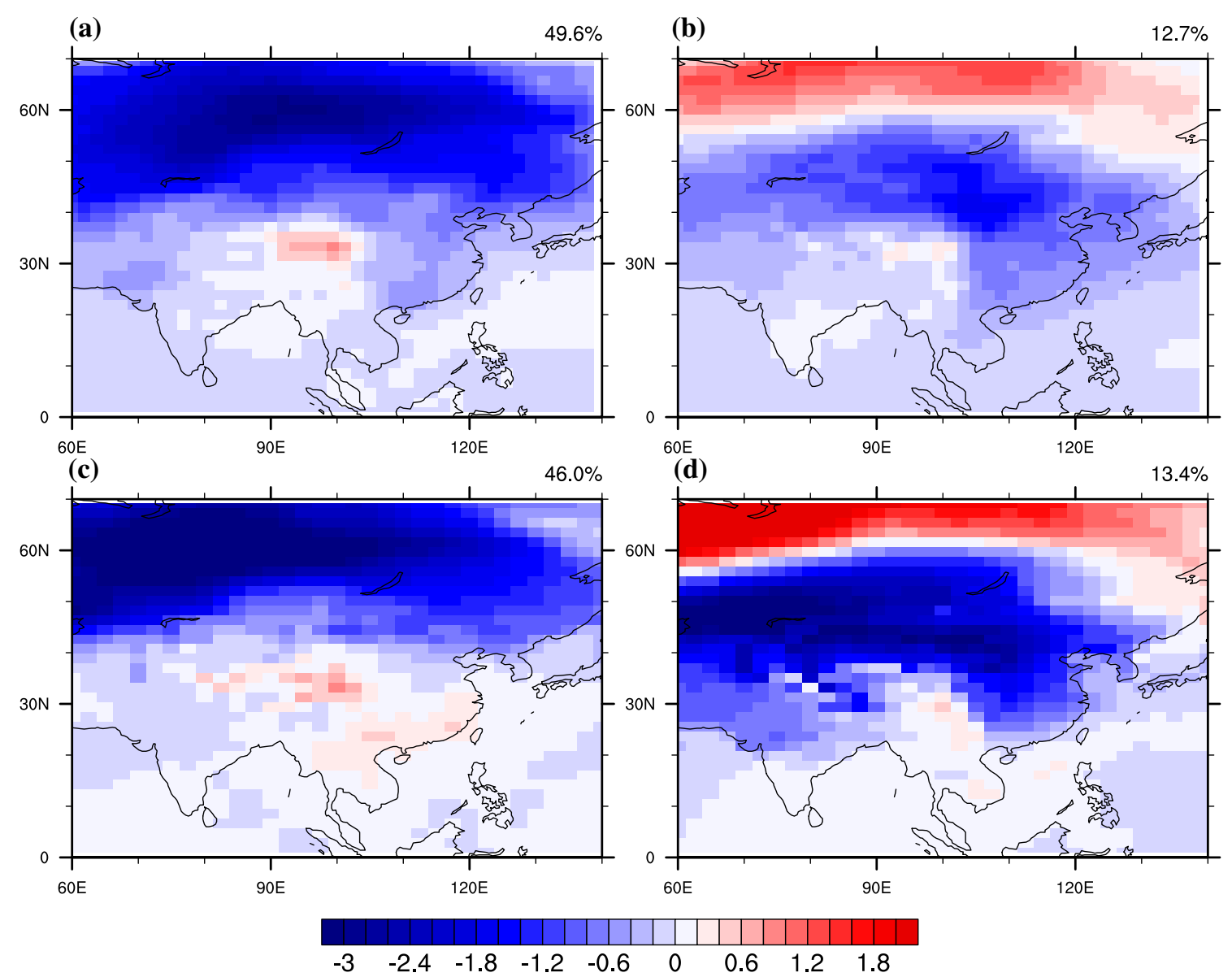

Fig. 2 The two leading EOF modes of the DJF mean surface temperature over Asia derived from the 20th century reanalysis (a, b) and control experiment $(\mathbf{c}, \mathbf{d})$

(a)

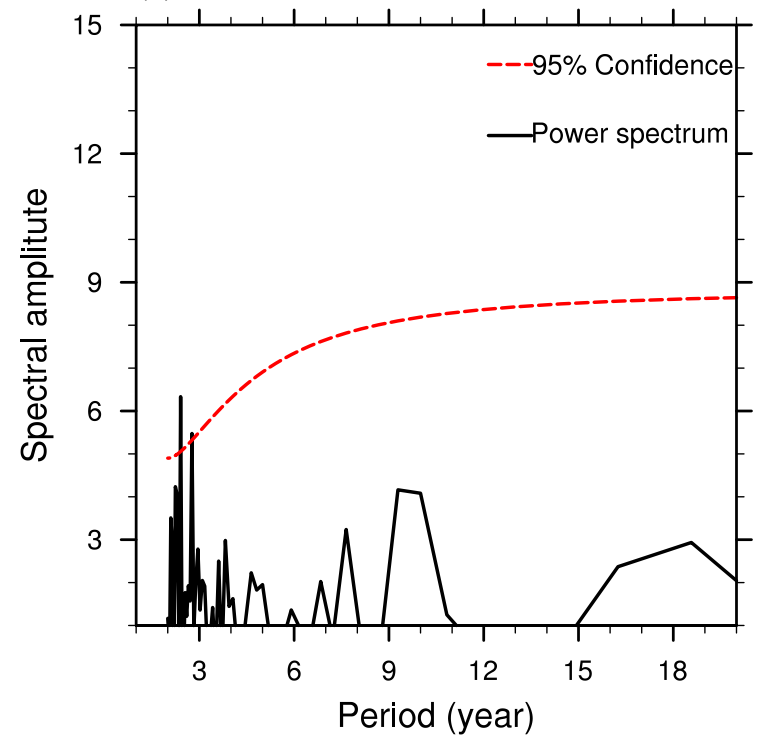

(b)

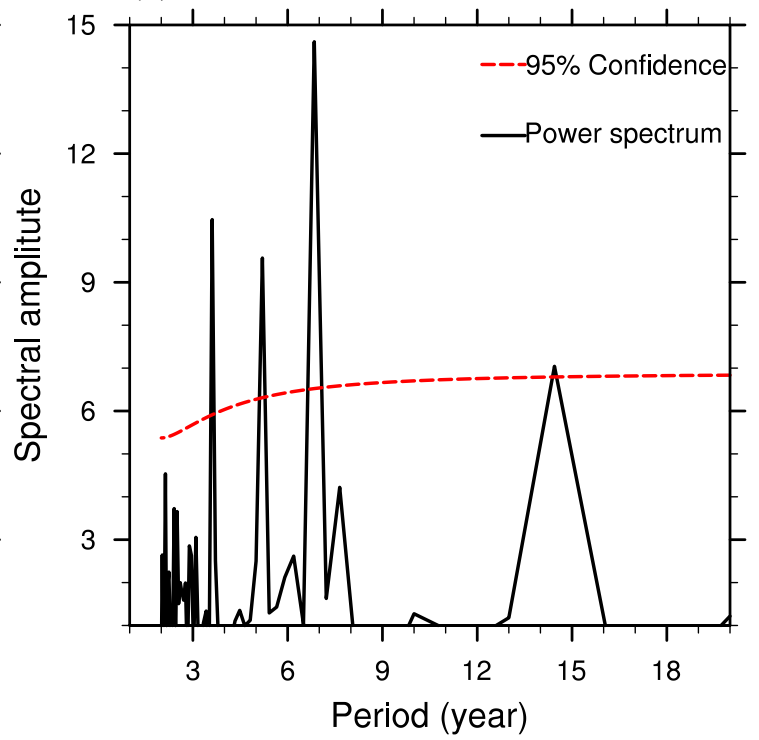

Fig. 3 Spectra of the leading principal components derived from a the 20th Century reanalysis and $\mathbf{b}$ the control experiment 

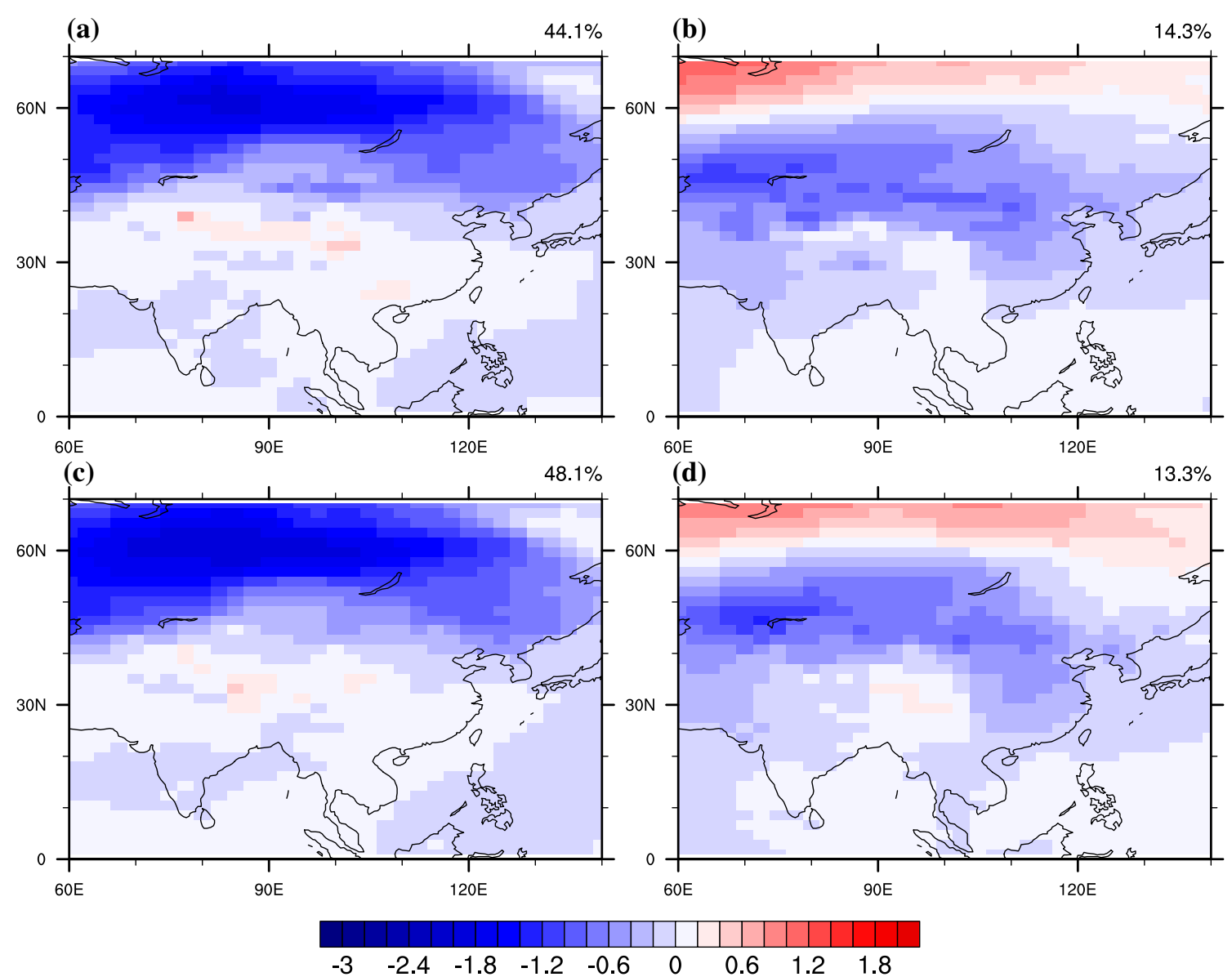

Fig. 4 Two leading EOF modes of the DJF mean surface temperature over Asia during strong 11-year solar cycle epoch (AD 1100-1235) (a, b) and weak 11-year solar cycle epoch (AD 1400-1535) (c, d) of four-member ensemble averaged solar-forcing experiments

interannual peak becomes insignificant. However, in the Weak Epoch, the interannual peaks remain dominant as in the control experiment. The quasi-15-year peak in the control experiment is absent during the Weak Epoch, but the strong 11-year solar cycle has shifted the decadal peak to around 12 years. Different from the PC1s, the spectra of PC2s during the Strong and Weak Epochs remain to be dominated by interannual oscillations as in the control run (figure not shown), suggesting that the 11-year solar forcing has little impact on the southern EOF mode of the AWM. The above results indicate that a strong 11-year solar cycle can generate decadal signals in the leading (northern) mode of the AWM variability. Additionally, in the individual single solar-only experiments, the decadal signals are variable, suggesting that the internal decadal variability dominates over the forced response in the individual experiments. To focus on solar-forcing impacts on the northern mode of the Asian winter monsoon, we examine the four-member ensemble averages, in which the random internal variability in each single experiment largely cancels each other so that the forced effect can be better detected.

To further investigate the linkage between the northern mode of the AWM variability and solar activity on decadal timescale, an 8 to 15-year bandpass filter was applied to the external forcing and the PC1 during the Strong Epoch. As shown in Fig. 6a, during the Strong Epoch, the leading mode of the AWM (PC1) is not simultaneously correlated with solar irradiance variability, rather, the significant maximum positive correlation occurs with 3-4 years delay after calculating the effective sample size (Bretherton et al. 1999). That means that the response of the leading mode of AWM variation reaches a peak after 3-4 years later following the maximum solar irradiance, namely, the cold northern Asia occurs about 3 years later after the peak solar radiation. 
(a)

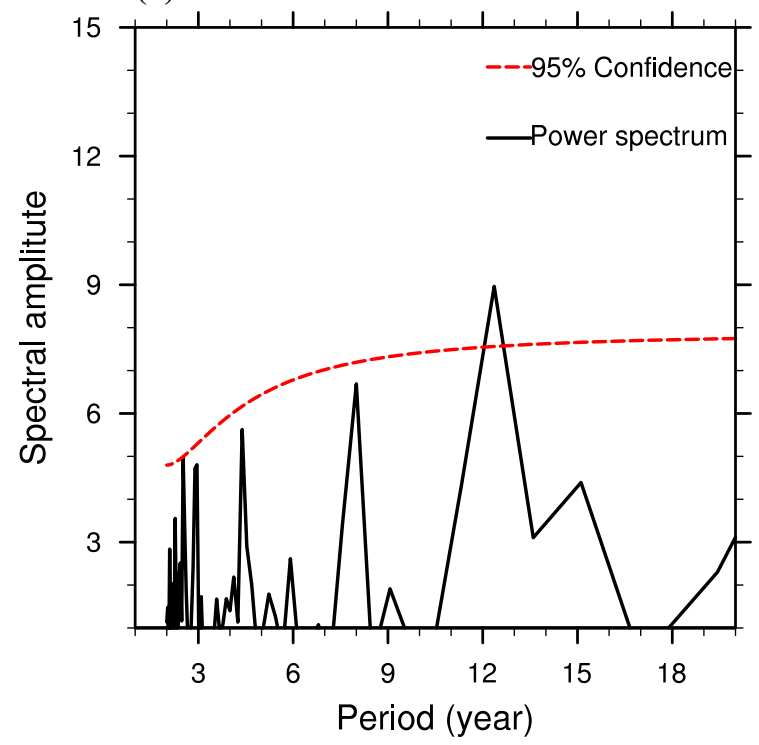

(b)

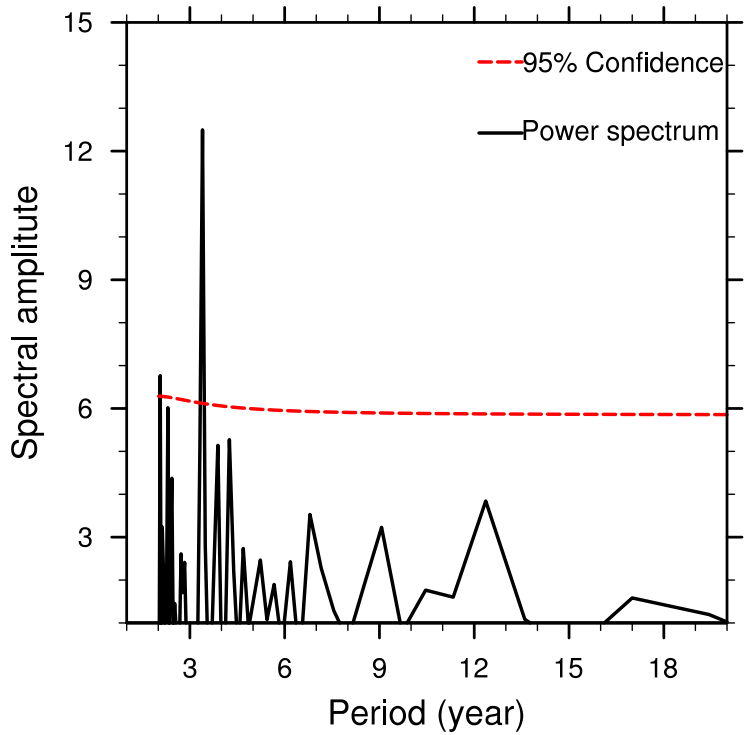

Fig. 5 Spectra of the leading principal components during the strong 11-year cycle epoch (a) and weak 11-year cycle epoch (b) derived from four-member ensemble averaged solar-forcing experiments

(a)

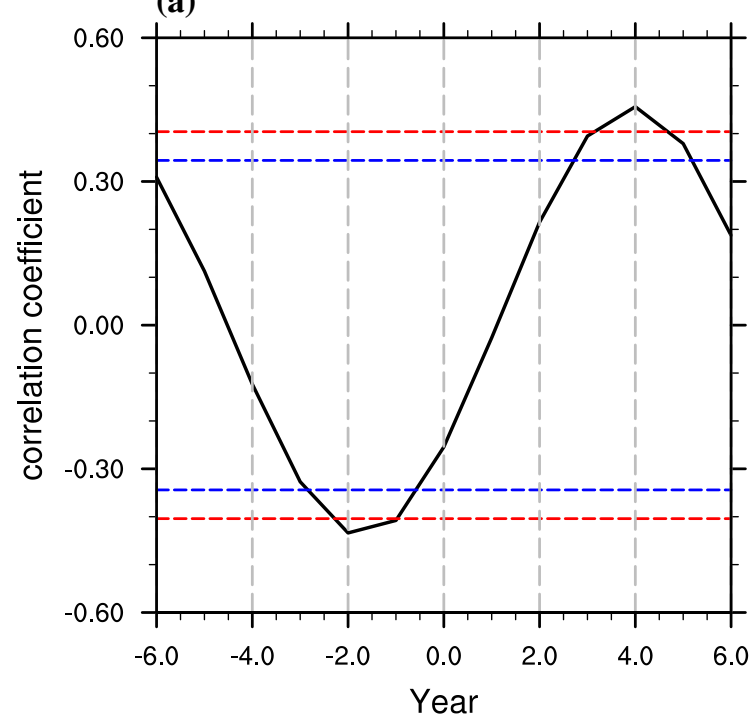

Fig. 6 The lead-lag correlation between the PC1 and the TSI (a), the accumulated TSI (b) during the strong 11-year cycle epoch (AD 1100-1235) derived from four-member ensemble averaged solar-

\section{Possible processes by which the 11-year solar cycle impacts the northern Asian winter}

The 3-4 years phase-delayed response is a peculiar feature. This peculiar feature is further perplexed by the fact that during winter, solar irradiance flux has little impacts (b)

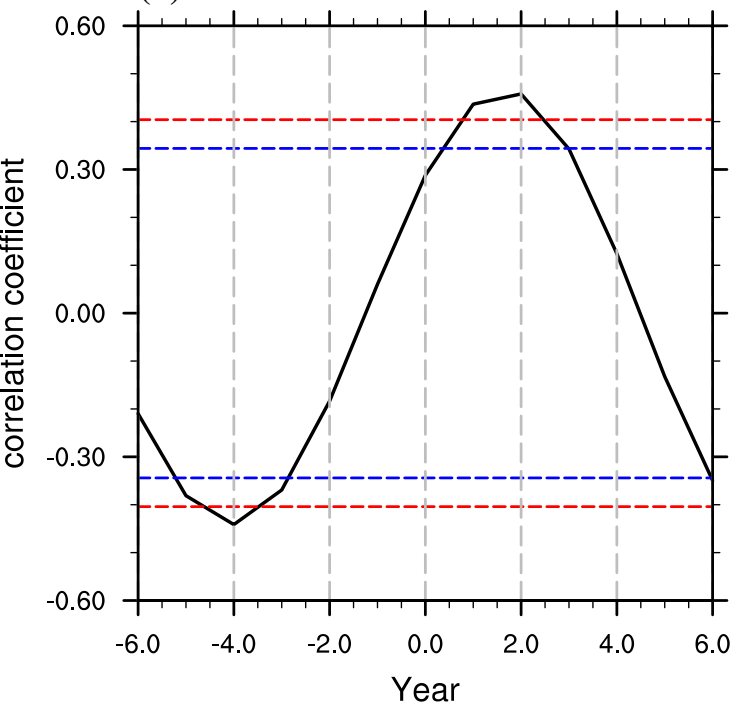

forcing experiments. The blue dashed lines are significant at the $90 \%$ confidence level, the red dashed lines are significant at the $95 \%$ confidence level, and the effective sample sizes are 22

on the northern high latitudes. The solar irradiance cycle should have strongest climate consequence during boreal summer when the northern hemisphere, especially the northern high latitudes, receive maximum solar radiation heating. Thus, the direct effects of solar forcing cannot explain this simulated winter phenomenon. In this section, we explore the two possible processes that can elucidate the aforementioned dilemmas. 
According to the thermodynamic equation, the maximum solar irradiance heating rate should result in a maximum rate of temperature change not the temperature itself. Assuming the solar irradiation flux is proportional to the diabatic heating rate, the accumulative TSI represents the accumulative solar heating effects. The result shown in Fig. 6b indeed indicates a generally simultaneous correlation (but most significant correlation with slight 1-2 years delay) between the accumulated TSI and the leading mode of the AWM on decadal timescale during the strong 11-year solar cycle epoch.

Ocean is an enormous heat reservoir. For the phasedelayed and seasonally-delayed responses, we hypothesized that the impacts of the enhanced summer solar forcing may be 'memorized' by ocean warming, which then feedback to the atmosphere later, affecting the northern Asian winter temperature. The temperature response should correspond to the accumulative solar heating effects. Evidences have shown that a small La Niña-like response in the peak solar year, followed a couple years later by a larger central Pacific El Niño-like response (Meehl and Arblaster 2009; Misios et al. 2016, 2019), which could induce a cooler-than-normal winter over Eurasia as shown by an AGCM experiment (Zhang et al. 2019). Other studies have shown that the cold Eurasia could be a consequence of the rapid decline of the preceding summer Arctic sea ice, especially over the Barents-Kara sea region where sea ice has largest seasonal and interannual variability (Honda et al. 2009; Cavalieri and Parkinson 2012; Inoue et al. 2012).

To reveal the possible processes by which the 11-year solar cycle may influence the cold winter in the northern Asia, first, we examined the correlation map between the SAT and the TSI with a 4-year delay (Fig. 7a). The winter SAT associated with the TSI shows an anomaly pattern similar to that of the northern mode of the AWM; meanwhile, significant warming occurs not only over the Arctic, but also over the eastern Pacific, resembling an El Niño-like sea surface temperature (SST) pattern. The result here suggests that the solar forcing could induce a cold northern Eurasia winter through both the TSI-induced Arctic warming and El Niño in the eastern Pacific. Next, we have examined whether an El Niño can affect AWM. As shown in Fig. 7b, the SAT anomalies associated with an El Niño features a slight warming over the northern Eurasia, suggesting that it is unlikely that a solar forcing-induced El Niño could generate the cold northern Eurasia. Considering the results shown in Fig. 7a and $b$ together, we suggest that the influence of the11-year solar cycle on the northern Asia winter monsoon is mainly via modulating the preceding summer Barents-Kara Sea ice and SST.

\section{Key mechanisms linking the 11-year solar cycle, Barents Sea ice, and cold winter in the northern Asia}

To show the role of Arctic sea ice melting and ocean warming, we present anomalies in the JJAS (June-September) sea ice concentration (Fig. 8a) and sea surface temperature (Fig. 8b) that are correlated with the solar forcing with a 4-year delay. Corresponding to the maximum solar radiative heating, the JJAS sea ice concentration over the Barents Sea and Kara Sea region shows a significant negative correlation, suggesting the sea ice melting in response to the solar radiative heating (Fig. 8a), corresponding to the generally warm SST (Fig. 8b). In addition, we describe JJAS mean sea ice concentration variability over the Barents Sea region $\left(70-82^{\circ} \mathrm{N}, 0-50^{\circ} \mathrm{E}\right)$ using a simple Barents Sea Ice Concentration (BSIC) index. The BSIC index during the Strong Epoch exhibits significant quasi-11-year energy peak (Fig. 9a), whereas the decadal signal is absent during the Weak Epoch (Fig. 9b). This indicates that the 11-year solar cycle can induce a 11-year peak in the JJAS mean sea ice concentration over the Barents Sea region, which has played a crucial role in the process of the phase-delayed response of the AWM to summer solar forcing.

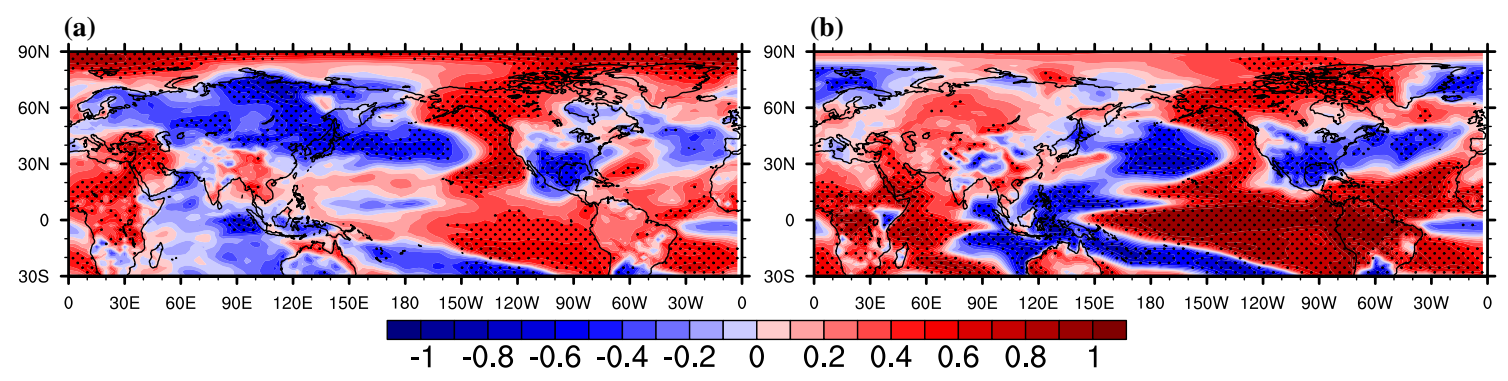

Fig. 7 Correlation maps of DJF mean surface air temperature with a the 11-year solar forcing with a 4-year delay, and with $\mathbf{b}$ the simultaneous NINO 3.4 index during the strong 11-year solar cycle epoch (AD 1100-1235). The NINO 3.4 index is defined by the SST anom- alies averaged over the equatorial central Pacific $\left(5^{\circ} \mathrm{S}-5^{\circ} \mathrm{N}, 170\right.$ $\left.120^{\circ} \mathrm{W}\right)$. An 8 to 15 -year-bandpass filter was used. The dotted areas are significant at the $95 \%$ confidence level 


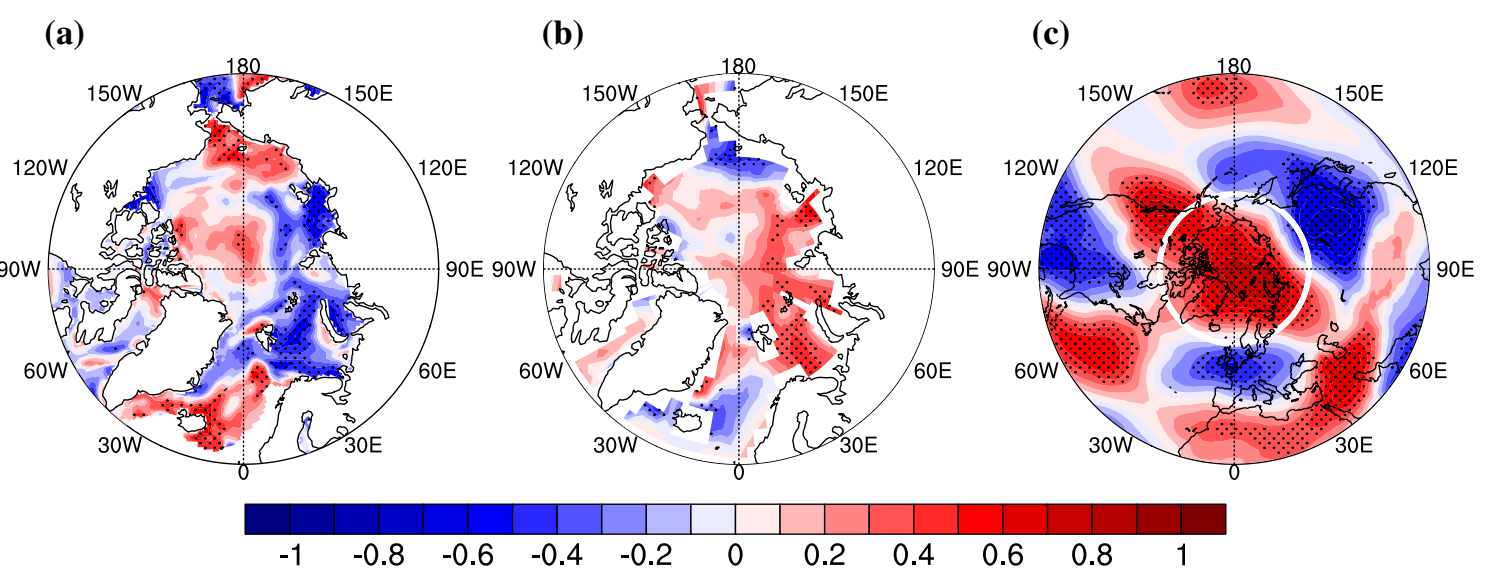

Fig. 8 4-year lagged correlation maps with references to the 11-year solar forcing: a the JJAS mean sea ice concentration anomalies, $\mathbf{b}$ the JJAS mean sea surface temperature anomalies, and $\mathbf{c}$ the DJF mean $500 \mathrm{hPa}$ Geopotential anomalies during the strong 11-year solar cycle epoch (AD 1100-1235). An 8 to 15-year-bandpass filter was used. The dotted areas are significant at the $90 \%$ confidence level. The white circles in $\mathbf{c}$ is used to outline the SIC domain shown in $\mathbf{a}$ and $\mathbf{b}$ (a)

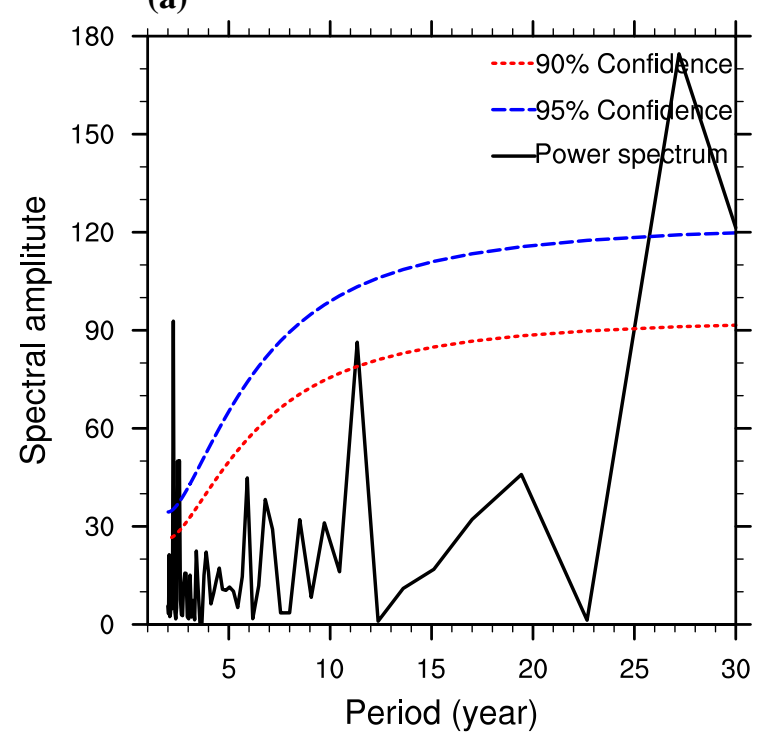

(b)

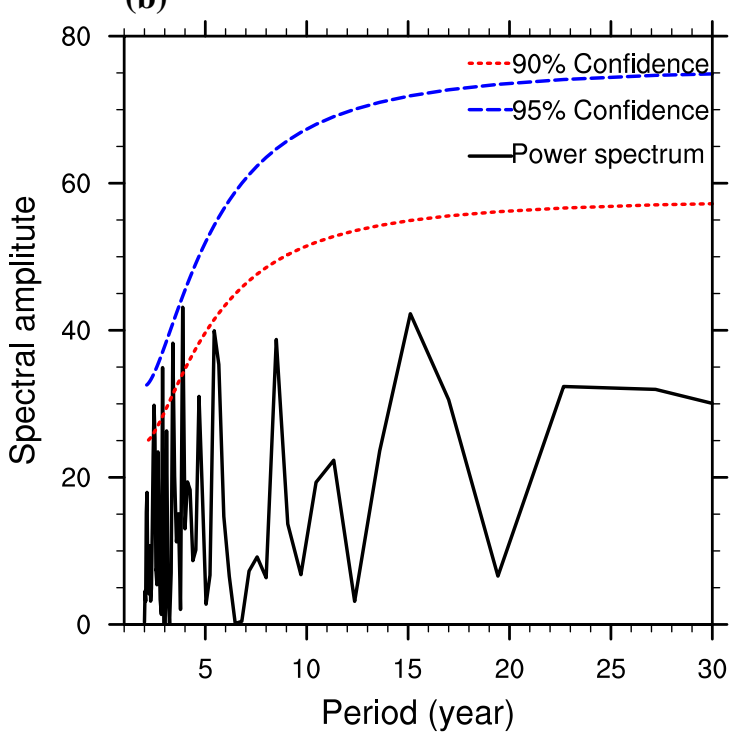

Fig. 9 Power spectrum of the BSIC index during a the strong 11-year cycle epoch (AD 1100-1235) and b weak 11-year cycle epoch (AD 14001535)

Second, the "Arctic memory" hypothesis can also explain the seasonally phase-delayed response. With the reduction of the sea ice over the Barents Sea during summer and autumn, the adjacent ocean is generally warmer than normal, which can persist into the ensuing winter due to the large heat capacity of the ocean, so that the DJF mean SAT exhibits abnormal warming over the Barents Sea and the Greenland Sea region (Fig. 7a). The winter Arctic warming features high-pressure anomalies over the entire Arctic (Fig. 8c). The winter Barents Sea warming can extend the Arctic high-pressure to Ural mountain region, which then perturbs westerly jet stream and further enhances and shifts the downstream
EA trough westward (Kug et al. 2015) (Fig. 8c). On the surface, the Mongolian-Siberian High shifts northwestward over Siberia, favoring the cold Arctic air mass intrusion into the high latitudes of Asian continent (Luo and Wang 2018). The Asian coldness extends from the Ural mountain all the way to the central North Pacific (Fig. 7a).

The explanation of the seasonal delayed response supports the observations. In fact, Cavalieri and Parkinson (2012) have suggested that the cold Siberian winter is significantly influenced by the diminishing Barents Sea ice in the preceding autumn. Luo and Wang (2018) have used the September-October mean SST anomalies in the Barents Sea 
region to predict the ensuing winter extremely cold days over the northern East Asia. The importance of the variation of the autumn Barents Sea ice in the winter climate system over Eurasia was also emphasized by Zhang et al. (2018).

\section{Conclusion and discussion}

The main findings concerning how the 11-year solar cycle could potentially affect the decadal variation of the AWM are summarized as follows.

1. The leading mode of the Asian winter monsoon (AWM), characterized by a cold northern Asia between 40 and $70^{\circ} \mathrm{N}$, is an intrinsic mode of AWM variability. However, the external forcing provided by strong 11-year solar cycle can excite a significant decadal signal in the leading AWM mode.

2. The response of the leading mode of the AWM reaches the strongest phase 4 years after the maximum solar irradiance. Thus, the 11-year solar cycle-excited decadal variation of the AWM is approximately in phase with the accumulated total solar irradiance.

3. The influence of the 11-year solar cycle on the AWM is mainly via modulating Arctic sea ice variation over the Barents-Kara Sea region during the preceding summer and fall. The Arctic sea ice melting reaches a maximum after a 4-year delay following the peak of the solar irradiance. The summer melting of sea ice causes winter Arctic warming north of $70^{\circ} \mathrm{N}$, which, in turn, generates extensive coldness over northern Asia and North Pacific through strengthening the Ural mountain pressure ridge and enhancing the Siberian High in the high latitude of Asia.

The new mechanism proposed in the present study emphasizes that the 11-year solar forcing can affect decadal variability of the northern hemisphere winter climate via its accumulative heating effects that are "memorized" by the Arctic sea ice melting during the preceding summer. This mechanism can explain two dilemmas, one is why the solar forcing variability in summer can affect winter climate, and the other is why there is a delay between the maximum solar irradiance and the AWM response, i.e., the Barents Sea warming and Siberian cooling. Our analysis is consistent with the result of Kug et al. (2015) in the sense that the Barents-Kara Sea warming induces the Ural mountain high anomaly, which can further shift the Mongolian-Siberian High northwestward, favoring intrusion of the cold Arctic air mass into the high latitudes of Asian continent. However, the Arctic high-pressure anomalies were not produced by the Barents-Kara Sea warming in the coupled global climate model experiments. This is not surprising because the sea ice and SST anomalies are not confined in the Barents-Kara Sea region (Fig. 8a). More appropriate experiments are required to distinguish the complex local atmosphere-ocean-sea ice interaction and remote atmospheric forcing. Meanwhile, the role of the 11-year solar cycle-induced Pacific warming on the cold northern Eurasia cannot be entirely ruled out, that calls for further studies.

Since the simulations do not include the 'top-down' effect of solar variability (Otto-Bliesner et al. 2016), the mechanism proposed in this paper depends almost entirely on the increased solar forcing acting on the ocean surface. However, in the presence of the 'top-down' mechanism, what is the resultant response of AWM calls for further investigation. The results of our study are based on numerical experiments performed using a single climate system model with a four-member ensemble. More ensemble members are desirable for a more reliable detection of the decadal signals. In addition, multi-model simulation results should be investigated to verify the results obtained from the single model used here.

Acknowledgements This work was supported by the National Key Research and Development Program of China (2016YFA0600401), National Natural Science Foundation of China (41420104002, 41671197 and 41631175), Natural Science Foundation of Jiangsu Higher Education Institutions (14KJA170002), Open Funds of State Key Laboratory of Loess and Quaternary Geology, Institute of Earth Environment, CAS (SKLLQG1820), Program of Innovative Research Team of Jiangsu Higher Education Institutions of China, and Priority Academic Program Development of Jiangsu Higher Education Institutions (164320H116). Financial support from the program of China Scholarships Council (NO. 201806860029). The CESM-LME data were generated by the CESM Paleoclimate Working Group at NACR. Support for the Twentieth Century Reanalysis Project dataset is provided by the U.S. Department of Energy, Office of Science Innovative and Novel Computational Impact on Theory and Experiment (DOE INCITE) program, and Office of Biological and Environmental Research (BER), and by the National Oceanic and Atmospheric Administration Climate Program Office. This is publication No. 10770 of the School of Ocean and Earth Science and Technology, publication No. 1399 of the International Pacific Research Center and publication No. 277 of the Earth System Modeling Center.

Open Access This article is distributed under the terms of the Creative Commons Attribution 4.0 International License (http://creativeco mmons.org/licenses/by/4.0/), which permits unrestricted use, distribution, and reproduction in any medium, provided you give appropriate credit to the original author(s) and the source, provide a link to the Creative Commons license, and indicate if changes were made.

\section{References}

Andrews MB, Knight JR, Gray LJ (2015) A simulated lagged response of the North Atlantic Oscillation to the solar cycle over the period 1960-2009. Environ Res Lett 10:54022 
Bretherton CS, Widmann M, Dymnikov VP et al (1999) The effective number of spatial degrees of freedom of a time-varying field. $\mathbf{J}$ Clim 12:1990-2009

Cavalieri DJ, Parkinson CL (2012) Arctic sea ice variability and trends, 1979-2010. Cryosphere 6:881

Chang C-P, Millard JE, Chen GTJ (1983) Gravitational character of cold surges during winter MONEX. Mon Weather Rev 111:293307. https://doi.org/10.1175/1520-0493(1983)111\%3c029 3:GCOCSD\%3e2.0.CO;2

Chen Z, Wu R, Chen W (2014) Distinguishing interannual variations of the northern and southern modes of the East Asian winter monsoon. J Clim 27:835-851

Chiodo G, Oehrlein J, Polvani LM et al (2019) Insignificant influence of the 11-year solar cycle on the North Atlantic Oscillation. Nat Geosci 12:94-99

Compo GP, Whitaker JS, Sardeshmukh PD et al (2011) The twentieth century reanalysis project. Q J R Meteorol Soc 137:1-28

Currie RG (1993) Luni-solar 18.6-and solar cycle 10-11-year signals in USA air temperature records. Int J Climatol 13:31-50

Frame THA, Gray LJ (2010) The 11-year solar cycle in ERA-40 data: an update to 2008. J Clim 23:2213-2222

Gray LJ, Scaife AA, Mitchell DM et al (2013) A lagged response to the 11 year solar cycle in observed winter Atlantic/European weather patterns. J Geophys Res Atmos 118:13-405

Gray LJ, Woollings TJ, Andrews M, Knight J (2016) Eleven-year solar cycle signal in the NAO and Atlantic/European blocking. Q J R Meteorol Soc 142:1890-1903

Haigh JD (1996) The impact of solar variability on climate. Science 272:981-984

Honda M, Inoue J, Yamane S (2009) Influence of low Arctic sea-ice minima on anomalously cold Eurasian winters. Geophys Res Lett 36:L08707

Ineson S, Scaife AA, Knight JR et al (2011) Solar forcing of winter climate variability in the Northern Hemisphere. Nat Geosci 4:753

Inoue J, Hori ME, Takaya K (2012) The role of Barents Sea ice in the wintertime cyclone track and emergence of a warm-Arctic coldSiberian anomaly. J Clim 25:2561-2568

Jin C, Liu J, Wang B et al (2019) Decadal variations of the East Asian summer monsoon forced by 11-year insolation cycle. J Clim $32: 2735-2745$

Kug J-S, Jeong J-H, Jang Y-S et al (2015) Two distinct influences of Arctic warming on cold winters over North America and East Asia. Nat Geosci 8:759

Luo X, Wang B (2018) Predictability and prediction of the total number of winter extremely cold days over China. Clim Dyn 50:1769-1784

Matthes K, Kuroda Y, Kodera K, Langematz U (2006) Transfer of the solar signal from the stratosphere to the troposphere: Northern winter. J Geophys Res Atmos 111:D06108

Meehl GA, Arblaster JM (2009) A lagged warm event-like response to peaks in solar forcing in the Pacific region. J Clim 22:3647-3660

Meehl GA, Arblaster JM, Branstator G, Van Loon H (2008) A coupled air-sea response mechanism to solar forcing in the Pacific region. J Clim 21:2883-2897

Meehl GA, Arblaster JM, Matthes K et al (2009) Amplifying the Pacific climate system response to a small 11-year solar cycle forcing. Science 325:1114-1118
Misios S, Mitchell DM, Gray LJ et al (2016) Solar signals in CMIP-5 simulations: effects of atmosphere-ocean coupling. Q J R Meteorol Soc 142:928-941

Misios S, Gray LJ, Knudsen MF, et al (2019) Slowdown of the Walker circulation at solar cycle maximum. Proc Natl Acad Sci 201815060

North GR, Bell TL, Cahalan RF, Moeng FJ (1982) Sampling errors in the estimation of empirical orthogonal functions. Mon Weather Rev 110:699-706

Otto-Bliesner BL, Brady EC, Fasullo J et al (2016) Climate variability and change since $850 \mathrm{CE}$ : an ensemble approach with the Community Earth System Model. Bull Am Meteorol Soc 97:735-754

Scaife AA, Arribas A, Blockley E et al (2014) Skillful long-range prediction of European and North American winters. Geophys Res Lett 41:2514-2519

Siscoe GL (1978) Solar-terrestrial influences on weather and climate. Nature 276:348

Soon WW (2005) Variable solar irradiance as a plausible agent for multidecadal variations in the Arctic-wide surface air temperature record of the past 130 years. Geophys Res Lett 32:L16712

Thiéblemont R, Matthes K, Omrani N-E et al (2015) Solar forcing synchronizes decadal North Atlantic climate variability. Nat Commun 6:8268

Van Loon H, Meehl GA (2012) The Indian summer monsoon during peaks in the 11 year sunspot cycle. Geophys Res Lett 39:L13701

Van Loon H, Meehl GA, Shea DJ (2007) Coupled air-sea response to solar forcing in the Pacific region during northern winter. J Geophys Res Atmos 112:D02108

Vieira LEA, Solanki SK, Krivova NA, Usoskin I (2011) Evolution of the solar irradiance during the Holocene. Astron Astrophys 531:A6

Wang B, Wu R, Lau KM (2001) Interannual variability of the Asian summer monsoon: contrasts between the Indian and the western North Pacific-East Asian monsoons. J Clim 14:4073-4090

Wang B, Wu Z, Chang C-P et al (2010) Another look at interannualto-interdecadal variations of the East Asian winter monsoon: the northern and southern temperature modes. J Clim 23:1495-1512

Zhang P, Wu Y, Simpson IR et al (2018) A stratospheric pathway linking a colder Siberia to Barents-Kara Sea sea ice loss. Sci Adv 4:eaat6025

Zhang P, Wang B, Wu Z (2019) Weak El Niño and winter climate in the mid-to high latitudes of Eurasia. J Clim 32:405-421

Zhou T, Gong D, Li J, Li B (2009) Detecting and understanding the multi-decadal variability of the East Asian Summer Monsoon-recent progress and state of affairs. Meteorol Zeitschrift $18: 455-467$

Publisher's Note Springer Nature remains neutral with regard to jurisdictional claims in published maps and institutional affiliations. 